\title{
Ventilatory response to added dead space and position in preterm infants at high risk age for SIDS
}

\begin{tabular}{|r|l|}
\hline Journal: & Pediatric Pulmonology \\
\hline Manuscript ID: & PPUL-10-0099.R1 \\
\hline Diley - Manuscript type: & Original Article \\
\hline Author: & 03-Aug-2010 \\
\hline Complete List of Authors: & $\begin{array}{l}\text { Saiki, Tolulope; King's College London, Division of Asthma, Allergy } \\
\text { and Lung Biology, MRC Asthma Centre for Allergic Mechanisms in } \\
\text { Asthma } \\
\text { Hannam, Simon; King's College London, Division of Asthma, Allergy } \\
\text { and Lung Biology, MRC Asthma Centre for Allergic Mechanisms in } \\
\text { Asthma } \\
\text { Rafferty, Gerrard; King's College London, Division of Asthma, } \\
\text { Allergy and Lung Biology, MRC Asthma Centre for Allergic } \\
\text { Mechanisms in Asthma } \\
\text { Milner, Anthony; King's College London, Division of Asthma, Allergy } \\
\text { and Lung Biology, MRC Asthma Centre for Allergic Mechanisms in } \\
\text { Asthma } \\
\text { Greenough, Anne; King's College London School of Medicine at } \\
\text { Guy's, King's College and St Thomas' Hospitals }\end{array}$ \\
\hline Keywords: & $\begin{array}{l}\text { prematurity, functional residual capacity, respiratory control, } \\
\text { respiratory muscle strength }\end{array}$ \\
\hline \hline
\end{tabular}

\section{SCHOLARONE $^{\text {M }}$ Manuscripts}


Ventilatory response to added dead space and position in preterm infants at high risk age for SIDS

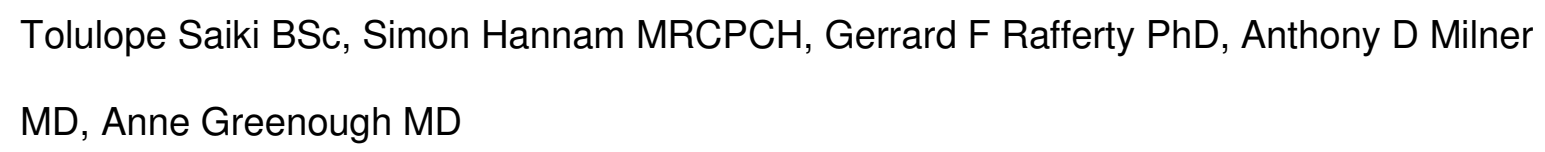

King's College London, MRC-Asthma Centre, Division of Asthma, Allergy and Lung Biology, London, SE5 9RS, United Kingdom

\section{Corresponding author:}

Anne Greenough,

Regional Neonatal Intensive Care Centre,

$4^{\text {th }}$ Floor Golden Jubilee Wing,

King's College Hospital,

Denmark Hill,

LONDON, SE5 9RS, UK.

Phone:+44 (0)20 32993037

Fax:+44 (0)20 32998284

e-mail: anne.greenough@kcl.ac.uk

Statement of financial support: Dr Saiki was supported by the Foundation for the Study of Infant Deaths.

Abbreviated title: $\quad$ Ventilatory response to added dead space 


\section{SUMMARY}

Objective: The vulnerability of prematurely born infants to Sudden Infant Death Syndrome (SIDS) in the prone position might be explained by a reduced ability to respond to a stress, such as hypercarbia, in that position; our objective, therefore, was to further explore the influence of position on the response to a stress.

Working hypothesis: The ability of prematurely born infants to respond to added dead space in the prone compared to the supine position would be impaired at the high risk age for SIDS.

Patients: Twenty infants, median gestational age of 30 (range 24-32) weeks were studied at a median postmenstrual age (PMA) of 45 weeks. In addition, comparisons were made to the results of 25 infants studied at 36 weeks PMA.

Methodology: Infants were studied supine and prone. Breath by breath minute volume was measured at baseline and after a dead space was incorporated into the breathing circuit; the time constant of the response was calculated. The pressure generated in the first $100 \mathrm{msec}$ of an occlusion $\left(\mathrm{P}_{0.1}\right)$, the maximum inspiratory pressure during an airway occlusion and functional residual capacity (FRC) were also measured in both positions.

Results: The median time constant was longer (38 (range 15-85) versus 26 (range 2-40) seconds $(p=0.002)) . P_{0.1}$ lower $(p=0.003)$ and FRC higher $(p=0.031)$ in the prone compared to the supine position. In the prone position, the time constant correlated with PMA $(p=0.047)$, ie. the rate of response to added dead space was significantly damped with increasing postnatal age up to the critical age for SIDS.

Conclusions: The dampened rate of response to added dead space in the prone compared to the supine position lends support to the hypothesis that a poorer response to a stress may contribute to prematurely born infants increased risk of SIDS in the prone position.

Key words: prematurity; functional residual capacity; respiratory control; respiratory muscle strength 


\section{INTRODUCTION}

Prone sleeping remains a significant risk factor for sudden infant death syndrome (SIDS) (1). Premature birth is also a risk factor for SIDS (2) and prematurely born infants may be particularly at risk of SIDS if they are slept prone (3). A possible explanation for the vulnerability of prematurely born infants to SIDS in the prone position might be that they are less able to respond to a stress, such as hypercarbia, in that position. The response to added deadspace (tube breathing) is a simple and reproducible method of assessing the ventilatory response to hypercarbia. Healthy infants born at term can compensate fully for an imposed dead space by increasing their minute ventilation (3). Intrauterine exposure to smoking, however, another known risk factor for SIDS (4), is associated with a dampened response to tube breathing in the perinatal period in term born babies (5). In addition, at 36 weeks postmenstrual age (PMA), we found that prematurely born infants had a dampened response to tube breathing in the prone compared to the supine position (6). The aim, therefore, of this study was to test the hypothesis that prematurely born infants' ability to respond to added dead space in the prone position would be impaired their high risk age for SIDS, that is $45-48$ weeks postmenstrual age (2). In addition, we wished to determine whether any differences between positions in the response to added dead space were related to differences in respiratory muscle strength and/or respiratory drive and whether the response to added dead space was influenced by postmenstrual age. 


\section{MATERIALS AND METHODS}

Infants born prior to 33 weeks of gestation were eligible for this study once they were older than 40 weeks PMA (ie post term). If their parents gave informed written consent, infants were studied supine and prone, after each position had been maintained up to three hours. The order in which the positions were studied was randomised between babies. In each position, first the infant's response to added dead space was examined and then their respiratory muscle strength, respiratory drive and lung volume were assessed. Infants were studied while in quiet sleep, with their eyes closed and breathing quietly.

To assess the response to added dead space, a face mask was placed over the infant's nose and mouth. Tubing ( $7.0 \mathrm{~mm}$ internal diameter) connected the face mask to a three way tap via which a bias flow of air (2 L/min) was delivered to the breathing circuit (Figure 1). A second tube $(7.0 \mathrm{~mm}$ internal diameter) led from the face mask to a pneumotachograph (PK Morgan, Rainham Kent, UK) via a Y connector. The length of the tube between the face mask and $Y$ connector was adjusted such that its volume was $4.4 \mathrm{mls} / \mathrm{kg}$ bodyweight, twice the generally accepted anatomical deadspace (7). A third tube connected the three way tap to the remaining part of the $\mathrm{Y}$ connector. The pneumotachograph was attached to a differential pressure transducer (MP45, Validyne Corporation, Northridge CA, USA) the signal from which was amplified (DC280; Validyne Corporation) and displayed in real time on a computer running Spectra software (version XX; Grove Medical, London UK) with $200 \mathrm{~Hz}$ analog to digital sampling (DAQ 16XE-50; National Instruments, Austin, TX, USA). Tidal volume was obtained by digital integration of the flow signal using the Spectra software and minute volume (MV), inspiratory (Ti), expiratory (Te) and total respiratory cycle (Ttot) times and respiratory rate were calculated breath by breath. Baseline recordings of respiratory flow were made with the three way tap in the neutral position, so that the bias flow of $2 \mathrm{~L} / \mathrm{min}$ of air to the face mask eliminated any dead space. When the tap was rotated the bias flow was fed via the third tube directly to the $Y$ connector and the pneumotachograph, so that the 
bias flow bypassed the facemask. This resulted in the dead space of the second tube being added to the infant's respiratory system. The infant then breathed through the additional dead space of $4.4 \mathrm{~mL} / \mathrm{kg}$ until the maximum minute ventilation (MMV) was deemed to have been reached. The breath by breath MV was plotted against time and a polynomial regression line (using Excel software (Microsoft Corp, Seattle, USA) was drawn through the data points collected from the point at which the additional dead space was added to the circuit. The response to added dead space was determined by calculating the time constant (Tc), defined as the time taken to achieve $63 \%$ of the increase in minute ventilation, and the change in MV expressed as a percentage of the baseline MV. The coefficient of repeatability of Tc had been previously shown to be 11 seconds (5) and at 36 weeks PMA was 7 seconds.

Respiratory muscle strength was assessed by measurement of the maximum pressure generated during crying against a sustained end expiratory airway occlusion (MIOP). During the procedure neck position was carefully controlled to avoid flexion. A pneumotachograph (GM Engineering, Kilwinning, UK), attached to a differential pressure transducer (Validyne MP45, range $+/-2 \mathrm{cmH}_{2} \mathrm{O}$, Validyne Corporation, Northridge CA, USA), was inserted in the distal end of a face mask which was held snugly, to avoid leaks, over the infant's nose and mouth. Airway pressure was measured from a side port on the pneumotachograph using a differential pressure transducer (Validyne MP 45, range $+/-100 \mathrm{cmH}_{2} \mathrm{O}$, Validyne Corporation, Northridge CA, USA). The signals from both transducers were amplified (Validyne CD280, Validyne Corporation, Northridge CA, USA) and displayed in real time on a computer running Labview software (version 4.0, National Instruments, Austin TX, USA) with $100 \mathrm{~Hz}$ analog to digital sampling (DAQ 16XE-50, National Instruments, Austin TX USA). Airway occlusions were performed using a T-piece containing a one way non-rebreathing valve attached to the distal end of the pneumotachograph. Airway occlusion was initiated by occluding the inspiratory limb of the T-piece during the preceding expiratory phase, the valve in the expiratory limb allowed expiration, but not inspiration. Each occlusion was maintained until the infant had made at least five respiratory efforts. At least five sets of occlusions were performed. The reported MIOP was the largest inspiratory pressure generated during 
the series of occlusions (8). Respiratory drive was assessed by measurement of the inspiratory pressure generated during the first 100 milliseconds of the first inspiratory effort during each occlusion $\left(P_{0.1}\right)$. The reported $P_{0.1}$ was the mean of the series of occlusions.

Lung volume can affect respiratory muscle strength, hence at the end of each three hour period, lung volume was assessed by measurement of functional residual capacity (FRC) using a helium gas dilution technique (9). The FRC system (Equilibrated Biosystems Inc, Series 7700 , Melville, NY) contained a rebreathing bag as the system reservoir and a specially designed infant circuit (total volume $95 \mathrm{~mL}$ ). A facemask (Rendell Baker, Laerdal, Norway) was held snugly over the infant's nose and mouth. Silicone putty was used around the mask to achieve an airtight seal. The facemask was connected to the re-breathing bag via a three-way valve, actuation of which switched the infant from breathing ambient room air to breathing the test gas mixture $\left(10 \% \mathrm{He}\right.$, balance $\left.\mathrm{O}_{2}\right)$ in the rebreathing bag. During the measurement, if there was no change in the helium concentration over a 15-second period, equilibration was deemed to have occurred. The initial and equilibration helium concentrations were used in the calculation of $\mathrm{FRC}$, which was corrected for oxygen consumption (assumed to be $7 \mathrm{ml} / \mathrm{kg} /$ minute) (10)) and for body temperature, pressure and water vapor-saturated conditions. FRC was measured twice in each position and the results of the paired measurements were averaged and related to body weight. The co-efficient of repeatability of $\mathrm{FRC}$ in non ventilated infants is $3.9 \mathrm{ml} / \mathrm{kg} \mathrm{(11).}$

\section{Statistical Analysis}

Differences in the results in the two positions were assessed for statistical significance using the paired Wilcoxon Rank Sum Test. Spearman's correlation coefficients were calculated to determine the strengths of any relationships between the change in the minute volume or the time constant of the response to the added dead space and MIOP or $\mathrm{P}_{0.1}$. To assess whether the response to added dead space post term was poorer post term than at 36 weeks PMA, 
we compared the results from this study to those we have previously published from 25 infants, median gestational age 30 (range 26-32 weeks) studied at 36 weeks PMA (6). Differences between results at 36 weeks PMA and post term were assessed for statistical significance using the Mann Whitney U-Test. Twelve infants were included in this and our previous study (6), differences in the time constant results in the two positions at 36 weeks PMA and post term were assessed for statistical significance using the paired Wilcoxon Rank Sum test. Using all the results from the two studies, Spearman's correlation co-efficients were calculated to determine the strength of any relationships between the change in minute volume or the time constant and postmenstrual age. Analysis was performed using SPSS version 12.0, SPSS Inc, Chicago, Illinois 60606, USA.

\section{Sample Size}

In a previous study (5), we demonstrated that the coefficient of repeatability of TC was 11 seconds. Recruitment of 20 infants allowed, with at least $80 \%$ power at the $5 \%$ level, detection of a difference in the Tc between positions of at least 11 seconds.

\section{Patients}

Twenty infants (10 males), median gestational age 30 (range 24-32) weeks and birthweight 1190 (SD 326) (range 543-1730) gm (mean ( \pm SD) z score $0 \pm 1$ ) were recruited. They were studied at a postmenstrual age of 45 (41-47) weeks and weight of 3.72 (SD 0.95) (range 1.85.3) $\mathrm{kgs}$ (mean $( \pm S D) z$ score $0 \pm 1$ ). Five infants were oxygen dependent beyond 36 weeks PMA, but none were oxygen dependent at the time of study. None of the infants were receiving any medication when studied. Three mothers had smoked during pregnancy. The twelve infants included in our previous study (6) and this study had a median gestational age of 29 (range 24-32) weeks and birth weight 1230 (range 730-1730) gms. The study was approved by the King's College Hospital Research Ethics Committee. 


\section{RESULTS}

The addition of the dead space resulted in an increase in minute volume in both the prone and supine positions (Table 1). The difference between positions in the percentage change in minute volume was not statistically significant. The time constant of the response was significantly longer in the prone compared to the supine position $(p=0.002)$ (Table 1) (Figure 2). There were no significant differences in the respiratory timings or minute ventilation at baseline between the two positions (Table 1). The median $T_{i}$ was significantly longer in the prone compared to the supine position after the dead space was added (Table 1).

The median MIOP tended to be lower in the prone compared to the supine position $(p=0.07)$, but there was no significant correlations between the response to tube breathing and MIOP in either position. The median $\mathrm{P}_{0.1}$ was significantly lower in the prone compared to the supine positions $(p=0.003)$, but there were no significant correlations between the response to tube breathing and $\mathrm{P}_{0.1}$ in either position. The median FRC was significantly higher in the prone compared to the supine position $(p=0.031)$ (Table 1$)$.

Comparisons of the results of the infants studied at 36 weeks PMA and those studied post term revealed no significant differences in the median changes in minute volume or the time constant, but that the median MIOP was significantly greater in both positions post term $(p<0.001)$ (Table 2$)$. The change in minute ventilation was not significantly correlated with postmenstrual age in either the supine $(p=0.697)$ or the prone $(p=0.25)$ position. The mean difference in the time constants between the prone and supine positions was 8.3 seconds at 36 weeks PMA and 21.3 seconds post term respectively. The mean difference between the difference at the two time periods was 13.4 seconds ( $95 \%$ confidence intervals of the differences was $-2.5,28.6)(p=0.098)$. In the twelve infants who had been assessed at 36 weeks PMA and post term, the median time constant at 36 weeks PMA in the supine position was 25 (range 10-51) seconds and in the prone position was 34 (range 15-96) seconds $(p=0.019)$ and post term in the supine position was 26 (range 2-40) seconds and in the prone 
position was 38 (range $15-85)$ seconds $(p=0.008)$. There was no significant difference in the difference in the time constant results in the supine and prone positions between the two time periods. Overall, the time constant of the response to added dead space had a significant positive correlation with postmenstrual age in the prone $(r=0.305, p=0.047)$, but not the supine $(r=0.031, p=0.844)$ position. 


\section{DISCUSSION}

We have demonstrated that at a high risk age for SIDS (2), the response to added dead space in prematurely born infants was poorer in the prone compared to the supine position, as the time constant was significantly longer in the prone position. Hypercarbia is the most important stimulus to ventilation during added dead space (tube breathing), as measurements in air and 30\% oxygen yielded similar results (12) and no effect of resistance was found in experiments involving prematurely born infants (12). Our results then suggest that prematurely born infants at the high risk age for SIDS have a dampened response to hypercarbia in the prone position. The time constant during tube breathing is shorter in active compared with quiet sleep (3). To avoid such a confounding effect, infants were always tested when they were in quiet sleep. Maternal smoking during pregnancy is associated with an impaired response to added dead space (5). Three infants studied had mothers who were smokers, but our results were not biased by their inclusion as we compared the response of all the infants in two positions.

The dampened response to added dead space in the prone position may indicate reduced respiratory drive in that position. Indeed we did find that the $P_{0.1}$ was significantly lower in the prone compared to the supine position. $\mathrm{P}_{0.1}$ is influenced by respiratory muscle strength, but there was no significant difference in the median MIOP between positions. As we had demonstrated previously (13), the median FRC was higher in the prone compared to the supine position. Although the difference was significant, however, the magnitude of the difference was relatively small and unlikely to influence MIOP (14). It is possible, however, that the difference in FRC may have affected the strength of the Hering-Breuer inflation reflex. The Hering-Breuer inflation reflex which terminates inspiration and prolongs expiration in response to lung inflation (15) is stronger in the prone compared to the supine position $(16,17)$. Differences in the strength of the reflex between positions in prematurely born infants have been shown to be significantly correlated with differences in lung volume (17). In addition, in healthy adults the strength of the Hering-Breuer reflex was directly 
proportional to increasing lung volume (18). A possible explanation for our results, then, is that the significantly increased FRC in the prone position was associated with increased feedback from pulmonary stretch receptors which reduced ventilatory drive as evidenced by a lower $\mathrm{P}_{0.1}$ and a longer time constant in response to added deadspace.

Ideally, to have assessed the effect of postmenstrual age on the response to dead space, we would have undertaken serial measurements on the same group of babies, but were unable to do this only in a subset of our study population. The same equipment and methodology, however, was used in both studies. Indeed, one of the researchers was involved in making certain of the measurements in both studies and the same team analysed the results of the two studies using the same techniques. The only difference in the two studies was in the first one (6), the infants were studied while awake and in the one currently reported the infants were studied while in quiet sleep. In quiet sleep there is less variability in minute volume than when infants are in active sleep or awake, but this would not affect the time constant of the response. We, thus, feel it is appropriate to pool the results of the two studies.

Despite the median MIOP being significantly greater post term than at 36 weeks PMA, the response to added dead space was not significantly better, suggesting respiratory muscle strength (above a crucial level) may not be a major determinant of the response to added dead space. There were no statistically significant differences in the time constants in either position post term compared to 36 weeks PMA. The paired analysis in the study population overall and in the subgroup, however, demonstrated the levels of significance were greater post term than at 36 weeks PMA, indicating that a greater proportion of the infants had longer time constants in the prone compared to the supine position post term than at 36 weeks PMA. We also found a significant correlation between the time constant of the response to added dead space and postmenstrual age in the prone position, that is, the response to added dead space was slower with increasing postmenstrual age. A possible explanation for the reduced response rate to added dead space with increasing postnatal age might be maturational changes in the Hering-Breuer inflation reflex. There are few 
longitudinal studies of maturational changes in the Hering-Breuer reflex, but in term born infants, the strength of the reflex appears to diminish between two and twelve months of age (19). In prematurely born infants an initial increase in the strength of the reflex from birth to 40 weeks PMA has been described, but the reflex strength was lower when the infants were examined four months after their expected date of delivery (20). Others (21) have demonstrated a reduction in the strength of the reflex in prematurely born infants from birth, but the study was performed over thirty years ago. Thus, it (21) would have included infants not exposed to either antenatal steroids or postnatal surfactant and with different lung function from the present population of very prematurely born infants. In addition, it is likely the infants were studied supine (21). We speculate that the strength of the Hering-Breuer reflex in the prone position may be maximal in prematurely born infants at the critical age for SIDS and could contribute to their reduced response to added deadspace.

In conclusion, we have demonstrated that prematurely born infants at the high risk age for SIDS had a poorer response to an added dead space in the prone compared to the supine position. In addition, the rate of response to the added dead space in the prone position was significantly damped with increasing postmenstrual age up to the critical age for SIDS. These findings lend support to the hypothesis that a poorer response to a stress may contribute to the increased vulnerability of prematurely born infants to SIDS in the prone position. 


\section{REFERENCES}

1. Vennemann MM, Bajanowski T, Brinkmann B, Jorch G, Sauerland C, Mitchell EA. Sleep environment risk factors for sudden infant death syndrome: the German Sudden Infant Death Syndrome Study. Pediatrics 2009;123(4):1162-1170.

2. Halloran DR, Alexander GR. Preterm delivery and age of SIDS death. Ann Epidemiol 2006;16(8):600-606.

3. Upton CJ, Milner AD, Stokes GM, Wilson AJ. Dynamic responses to tube breathing during the first 10 days of life. Pediatr Pulmonol 1990;9(2):72-79.

4. Chong DS, Yip PS, Karlberg J. Maternal smoking: an increasing unique risk factor for sudden infant death syndrome in Sweden. Acta Paediatr 2004;93(4):471-478.

5. Bhat RY, Broughton S, Khetriwal B, Rafferty GF, Hannam S, Milner AD, Greenough A. Dampened ventilatory response to added dead space in newborns of smoking mothers. Arch Dis Child Fetal Neonatal Ed 2005;90(4):F316-319.

6. Rao H, Saiki T, Landolfo F, Smith AP, Hannam S, Rafferty GF, Milner AD, Greenough A. Position and ventilatory response to added dead space in prematurely born infants. Pediatr Pulmonol 2009;44(4):387-391

7. Oyen N, Markestad T, Skaerven R, Irgens LM, Helweg-Larsen K, Alm B, Norvenius G, Wennergren G. Combined effects of sleeping position and prenatal risk factors in sudden infant death syndrome: the Nordic Epidemiological SIDS Study. Pediatrics $1997 ; 100(4): 613-621$.

8. Dimitriou G, Greenough A, Pink L, McGhee A, Hickey A, Rafferty GF. Effect of posture on oxygenation and respiratory muscle strength in convalescent infants. Arch Dis Child Fetal Neonatal Ed 2002;86(3):F147-150.

9. Bhat RY, Leipala JA, Singh NR, Rafferty GF, Hannam S, Greenough A. Effect of posture on oxygenation, lung volume, and respiratory mechanics in premature infants studied before discharge. Pediatrics 2003;112(1 Pt 1):29-32.

10. Hey EN. The relation between environmental temperature and oxygen consumption in the new-born baby. J Physiol 1969;200(3):589-603. 
11. Dimitriou G, Greenough A, Laubscher B. Lung volume measurements immediately after extubation by prediction of "extubation failure" in premature infants. Pediatr Pulmonol 1996;21(4):250-254.

12. Upton CJ. Apnoea of prematurity. MD University of Nottingham 1994.

13. Saiki T, Rao H, Landolfo F, Smith A, Hannam S, Rafferty GF, Greenough A. Sleeping position, oxygenation and lung function in prematurely born infants studied post term. Arch Dis Child 2009;94:F133-137.

14. McCool FD, Tzelepis GE, Leith DE, Hoppin FG, Jr. Oxygen cost of breathing during fatiguing inspiratory resistive loads. J Appl Physiol 1989;66(5):2045-2055.

15. Hering, E. Die Selbststeuerung der Atmung durch den Nervus vagus. Wien: Sitzungsberichte der mathematisch - naturwissenschaftlichen Klasse der kaiserlichen Akademie der Wissenschaften Abtheilung, str. 1868;57:672-677.

16. Hand IL, Noble L, Geiss D. The effects of positioning on the Hering-Breuer reflex in the preterm infant. Pediatr Pulmonol 2007;42(1):37-40.

17. Landolfo F, Saiki T, Peacock J, Hannam S, Rafferty GF, Greenough A. Hering-Breuer reflex, lung volume and position in prematurely born infants. Pediatr Pulmonol 2008;43(8):767-771.

18. Tryfon S, Kontakiotis T, Mavrofridis E, Patakas D. Hering-Breuer reflex in normal adults and in patients with chronic obstructive pulmonary disease and interstitial fibrosis. Respiration 2001;68(2):140-144.

19. Rabbette PS, Costeloe KL, Stocks J. Persistence of the Hering-Breuer reflex beyond the neonatal period. J Appl Physiol 1991;71(2):474-480.

20. Stocks J, Dezateux C, Hoo AF, Rabbette PS, Costeloe K, Wade A. Delayed maturation of Hering-Breuer inflation reflex activity in preterm infants. Am J Respir Crit Care Med 1996;154(5):1411-1417.

21. Olinsky A, Bryan MH, Bryan AC. Influence of lung inflation on respiratory control in neonates. J Appl Physiol 1974;36(4):426-429. 


\section{FIGURE LEGEND:}

Figure 1: Apparatus used to measure the response to added dead space.

(A) The arrows show the direction of gas flow before the dead space is added.

(B) When the three way tap is turned to be in the vertical position, this diverts the bias flow from the face mask and the infant has to breathe from the added dead space tube.

Figure 2: The time constants of the response related to position at 36 weeks PMA and post term

- individual data are demonstrated by linked data points. 
Table 1: The response to added deadspace in the prone and supine position

Data are demonstrated as median (range)

Prone Supine

p

Minute ventilation $(\mathrm{ml} / \mathrm{min} / \mathrm{kg})$

Baseline

Maximum post dead space

Following addition of dead space:

Change in minute ventilation (\%)

Change in tidal volume (\%)

Change in respiratory rate (\%)

Time constant (secs)

Respiratory rate (bpm)

Baseline

Added dead space

Tidal volume $(\mathrm{ml} / \mathrm{kg})$

Baseline

Added dead space

Ti (sec)

Baseline

Added dead space

Te (sec)

Baseline

Added dead space

Ttot (sec)

Baseline

Added dead space

MIOP $\left(\mathrm{cm} \mathrm{H}_{2} \mathrm{O}\right.$ )

$\mathrm{P}_{0.1}\left(\mathrm{~cm} \mathrm{H} \mathrm{H}_{2} \mathrm{O}\right)$

$\mathrm{P}_{0.1} /$ MIOP ratio

FRC $(\mathrm{ml} / \mathrm{kg})$
235 (71-446)

402 (104-771)

$229(105-537)$

0.575

387 (138-692)

0.629

$66(17-311)$

$32(-14-136)$

$3(-8-71)$

$38(15-85)$

72 (3-298)

0.794

$41(-5-222)$

0.654

$6(-7-31)$

0.822

$25.5(2-39.7)$

0.002

54 (35-91)

57 (39-98)

$55(37-87)$

0.167

59 (39-94)

0.211

$4.3(1.5-9.5)$

$3.6(2.1-8.5)$

0.191

$6.2(1.8-10.8)$

$5.9(2.1-10)$

0.287

$0.56(0.26-0.88)$

$0.54(0.30-0.91)$

0.108

$0.56(0.29-0.92)$

$0.52(0.33-0.71)$

0.030

$0.52(0.40-1.02)$

$0.56(0.33-0.87)$

0.313

$0.51(0.36-0.88)$

$0.49(0.33-0.71)$

0.331

$1.12((0.66-1.71)$

$1.11(0.63-1.58)$

0.156

$1.08((0.67-1.71)$

$63.8(47.9-104.6)$

$3.82(2.18-6.21)$

$0.06(0.03-0.11)$

$30.2(21.4-41.9)$
$1.04(0.62-1.56)$

0.073

$66.6(50.6-112.9)$

0.070

$4.72(2.65-9.99)$

0.003

$0.07(0.02-0.14)$

0.033

$26.9(18.7-40.7)$

0.031 
Table 2: Comparison of data at 36 weeks PMA and post term.

Data are demonstrated as median (range)

36 weeks PMA

\% change in MV

Supine

Prone

$85.4(6.5-242)$

$60.3(14.8-174)$

Time constant (secs)

Supine

Prone

$\operatorname{MIOP}\left(\mathrm{cm} \mathrm{H}_{2} \mathrm{O}\right)$

Supine

Prone

$P_{0.1}\left(\mathrm{~cm} \mathrm{H}_{2} \mathrm{O}\right)$

Supine

Prone

$\mathrm{P}_{0.1} /$ MIOP ratio

Supine

Prone
$0.121(0.05-0.26)$

$$
22(6-92)
$$

$26(8-106)$

$36.9(13.8-63.8)$

$25.9(16.8-53)$

$3.66(1.87-8.77)$

$2.64(1.39-13.20)$

$4.72(2.65-9.99)$

$3.82(2.1-6.21)$

$0.071(0.02-0.14)$

$0.105(0.03-0.33)$

$26(2-40)$

$38(15-85)$
Post term

p

$71.6(2.6-298)$

0.315

$66.1(16.9-311)$

0.553

0.819

0.201

$66.6(50.6-112.9) \quad<0.001$

$63.8(47.9-104.6) \quad<0.001$

45

46

47

48

49

50

51

52

53

54

55

56

57

58

59

60 


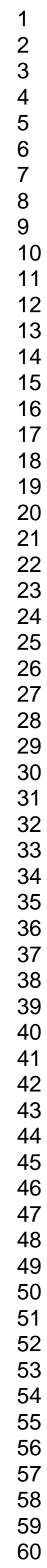

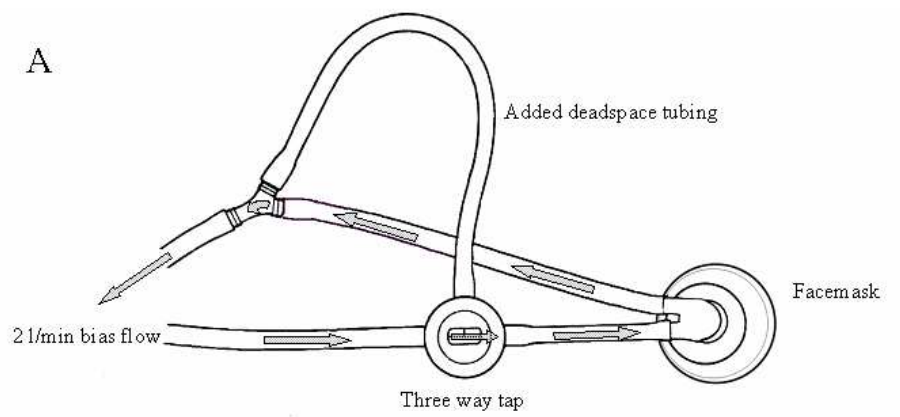

B

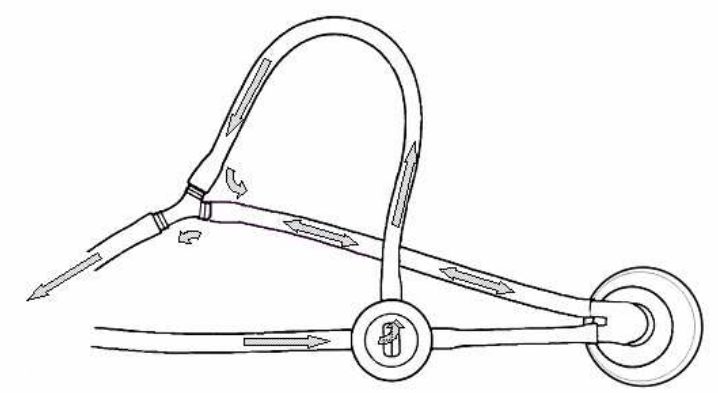

$254 \times 190 \mathrm{~mm}(96 \times 96$ DPI)

John Wiley \& Sons, Inc. 


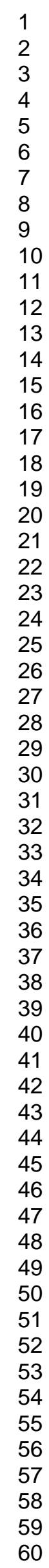

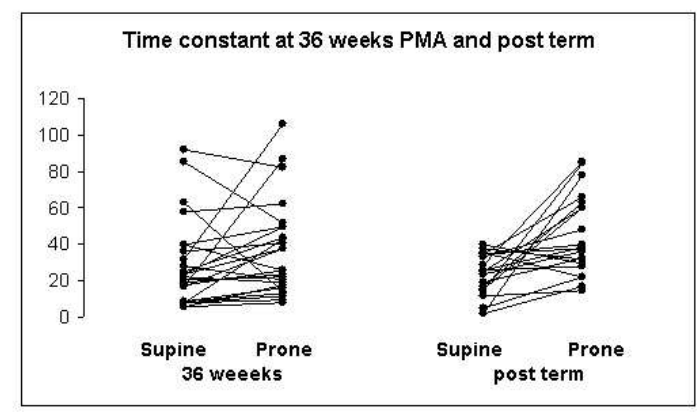

$254 \times 190 \mathrm{~mm}(96 \times 96 \mathrm{DPI})$

John Wiley \& Sons, Inc. 
Ventilatory response to added dead space and position in preterm infants at high risk age for SIDS

\author{
Tolulope Saiki BSc, Simon Hannam MRCPCH, Gerrard F Rafferty PhD, Anthony D Milner \\ MD, Anne Greenough MD
}

King's College London, MRC-Asthma Centre, Division of Asthma, Allergy and Lung Biology, London, SE5 9RS, United Kingdom

\title{
Corresponding author:
}

Anne Greenough,

Regional Neonatal Intensive Care Centre,

$4^{\text {th }}$ Floor Golden Jubilee Wing,

King's College Hospital,

Denmark Hill,

LONDON, SE5 9RS, UK.

Phone:+44 (0)20 32993037

Fax:+44 (0)20 32998284

e-mail: anne.greenough@kcl.ac.uk

Statement of financial support: Dr Saiki was supported by the Foundation for the Study of Infant Deaths.

Abbreviated title: $\quad$ Ventilatory response to added dead space 


\section{SUMMARY}

Objective: The vulnerability of prematurely born infants to Sudden Infant Death Syndrome (SIDS) in the prone position might be explained by a reduced ability to respond to a stress, such as hypercarbia, in that position; our objective, therefore, was to further explore the influence of position on the response to a stress.

Working hypothesis: The ability of prematurely born infants to respond to added dead space in the prone compared to the supine position would be impaired at the high risk age for SIDS.

Patients: Twenty infants, median gestational age of 30 (range 24-32) weeks were studied at a median postmenstrual age (PMA) of 45 weeks. In addition, comparisons were made to the results of 25 infants studied at 36 weeks PMA.

Methodology: Infants were studied supine and prone. Breath by breath minute volume was measured at baseline and after a dead space was incorporated into the breathing circuit; the time constant of the response was calculated. The pressure generated in the first $100 \mathrm{msec}$ of an occlusion $\left(\mathrm{P}_{0.1}\right)$, the maximum inspiratory pressure during an airway occlusion and functional residual capacity (FRC) were also measured in both positions.

Results: The median time constant was longer (38 (range 15-85) versus 26 (range 2-40) seconds $(p=0.002)) . P_{0.1}$ lower $(p=0.003)$ and FRC higher $(p=0.031)$ in the prone compared to the supine position. In the prone position, the time constant correlated with PMA $(p=0.047)$, ie. the rate of response to added dead space was significantly damped with increasing postnatal age up to the critical age for SIDS.

Conclusions: The dampened rate of response to added dead space in the prone compared to the supine position lends support to the hypothesis that a poorer response to a stress may contribute to prematurely born infants increased risk of SIDS in the prone position.

Key words: prematurity; functional residual capacity; respiratory control; respiratory muscle strength 


\section{INTRODUCTION}

Prone sleeping remains a significant risk factor for sudden infant death syndrome (SIDS) (1). Premature birth is also a risk factor for SIDS (2) and prematurely born infants may be particularly at risk of SIDS if they are slept prone (3). A possible explanation for the vulnerability of prematurely born infants to SIDS in the prone position might be that they are less able to respond to a stress, such as hypercarbia, in that position. The response to added deadspace (tube breathing) is a simple and reproducible method of assessing the ventilatory response to hypercarbia. Healthy infants born at term can compensate fully for an imposed dead space by increasing their minute ventilation (3). Intrauterine exposure to smoking, however, another known risk factor for SIDS (4), is associated with a dampened response to tube breathing in the perinatal period in term born babies (5). In addition, at 36 weeks postmenstrual age (PMA), we found that prematurely born infants had a dampened response to tube breathing in the prone compared to the supine position (6). The aim, therefore, of this study was to test the hypothesis that prematurely born infants' ability to respond to added dead space in the prone position would be impaired their high risk age for SIDS, that is $45-48$ weeks postmenstrual age (2). In addition, we wished to determine whether any differences between positions in the response to added dead space were related to differences in respiratory muscle strength and/or respiratory drive and whether the response to added dead space was influenced by postmenstrual age. 


\section{MATERIALS AND METHODS}

Infants born prior to 33 weeks of gestation were eligible for this study once they were older than 40 weeks PMA (ie post term). If their parents gave informed written consent, infants were studied supine and prone, after each position had been maintained up to three hours. The order in which the positions were studied was randomised between babies. In each position, first the infant's response to added dead space was examined and then their respiratory muscle strength, respiratory drive and lung volume were assessed. Infants were studied while in quiet sleep, with their eyes closed and breathing quietly.

To assess the response to added dead space, a face mask was placed over the infant's nose and mouth. Tubing ( $7.0 \mathrm{~mm}$ internal diameter) connected the face mask to a three way tap via which a bias flow of air $(2 \mathrm{~L} / \mathrm{min})$ was delivered to the breathing circuit (Figure 1$)$. A second tube $(7.0 \mathrm{~mm}$ internal diameter) led from the face mask to a pneumotachograph (PK Morgan, Rainham Kent, UK) via a Y connector. The length of the tube between the face mask and $Y$ connector was adjusted such that its volume was $4.4 \mathrm{mls} / \mathrm{kg}$ bodyweight, twice the generally accepted anatomical deadspace (7). A third tube connected the three way tap to the remaining part of the $\mathrm{Y}$ connector. The pneumotachograph was attached to a differential pressure transducer (MP45, Validyne Corporation, Northridge CA, USA) the signal from which was amplified (DC280; Validyne Corporation) and displayed in real time on a computer running Spectra software (version XX; Grove Medical, London UK) with $200 \mathrm{~Hz}$ analog to digital sampling (DAQ 16XE-50; National Instruments, Austin, TX, USA). Tidal volume was obtained by digital integration of the flow signal using the Spectra software and minute volume (MV), inspiratory (Ti), expiratory (Te) and total respiratory cycle (Ttot) times and respiratory rate were calculated breath by breath. Baseline recordings of respiratory flow were made with the three way tap in the neutral position, so that the bias flow of $2 \mathrm{~L} / \mathrm{min}$ of air to the face mask eliminated any dead space. When the tap was rotated the bias flow was fed via the third tube directly to the $Y$ connector and the pneumotachograph, so that the 
bias flow bypassed the facemask. This resulted in the dead space of the second tube being added to the infant's respiratory system. The infant then breathed through the additional dead space of $4.4 \mathrm{~mL} / \mathrm{kg}$ until the maximum minute ventilation (MMV) was deemed to have been reached. The breath by breath MV was plotted against time and a polynomial regression line (using Excel software (Microsoft Corp, Seattle, USA) was drawn through the data points collected from the point at which the additional dead space was added to the circuit. The response to added dead space was determined by calculating the time constant (Tc), defined as the time taken to achieve $63 \%$ of the increase in minute ventilation, and the change in MV expressed as a percentage of the baseline MV. The coefficient of repeatability of Tc had been previously shown to be 11 seconds (5) and at 36 weeks PMA was 7 seconds.

Respiratory muscle strength was assessed by measurement of the maximum pressure generated during crying against a sustained end expiratory airway occlusion (MIOP). During the procedure neck position was carefully controlled to avoid flexion. A pneumotachograph (GM Engineering, Kilwinning, UK), attached to a differential pressure transducer (Validyne MP45, range $+/-2 \mathrm{cmH}_{2} \mathrm{O}$, Validyne Corporation, Northridge CA, USA), was inserted in the distal end of a face mask which was held snugly, to avoid leaks, over the infant's nose and mouth. Airway pressure was measured from a side port on the pneumotachograph using a differential pressure transducer (Validyne MP 45, range $+/-100 \mathrm{cmH}_{2} \mathrm{O}$, Validyne Corporation, Northridge CA, USA). The signals from both transducers were amplified (Validyne CD280, Validyne Corporation, Northridge CA, USA) and displayed in real time on a computer running Labview software (version 4.0, National Instruments, Austin TX, USA) with $100 \mathrm{~Hz}$ analog to digital sampling (DAQ 16XE-50, National Instruments, Austin TX USA). Airway occlusions were performed using a T-piece containing a one way non-rebreathing valve attached to the distal end of the pneumotachograph. Airway occlusion was initiated by occluding the inspiratory limb of the T-piece during the preceding expiratory phase, the valve in the expiratory limb allowed expiration, but not inspiration. Each occlusion was maintained until the infant had made at least five respiratory efforts. At least five sets of occlusions were performed. The reported MIOP was the largest inspiratory pressure generated during 
the series of occlusions (8). Respiratory drive was assessed by measurement of the inspiratory pressure generated during the first 100 milliseconds of the first inspiratory effort during each occlusion $\left(P_{0.1}\right)$. The reported $P_{0.1}$ was the mean of the series of occlusions.

Lung volume can affect respiratory muscle strength, hence at the end of each three hour period, lung volume was assessed by measurement of functional residual capacity (FRC) using a helium gas dilution technique (9). The FRC system (Equilibrated Biosystems Inc, Series 7700 , Melville, NY) contained a rebreathing bag as the system reservoir and a specially designed infant circuit (total volume $95 \mathrm{~mL}$ ). A facemask (Rendell Baker, Laerdal, Norway) was held snugly over the infant's nose and mouth. Silicone putty was used around the mask to achieve an airtight seal. The facemask was connected to the re-breathing bag via a three-way valve, actuation of which switched the infant from breathing ambient room air to breathing the test gas mixture $\left(10 \% \mathrm{He}\right.$, balance $\left.\mathrm{O}_{2}\right)$ in the rebreathing bag. During the measurement, if there was no change in the helium concentration over a 15-second period, equilibration was deemed to have occurred. The initial and equilibration helium concentrations were used in the calculation of FRC, which was corrected for oxygen consumption (assumed to be $7 \mathrm{ml} / \mathrm{kg} /$ minute) (10)) and for body temperature, pressure and water vapor-saturated conditions. FRC was measured twice in each position and the results of the paired measurements were averaged and related to body weight. The co-efficient of repeatability of $\mathrm{FRC}$ in non ventilated infants is $3.9 \mathrm{ml} / \mathrm{kg}(11)$.

\section{Statistical Analysis}

Differences in the results in the two positions were assessed for statistical significance using the paired Wilcoxon Rank Sum Test. Spearman's correlation coefficients were calculated to determine the strengths of any relationships between the change in the minute volume or the time constant of the response to the added dead space and MIOP or $\mathrm{P}_{0.1}$. To assess whether the response to added dead space post term was poorer post term than at 36 weeks PMA, 
we compared the results from this study to those we have previously published from 25 infants, median gestational age 30 (range 26-32 weeks) studied at 36 weeks PMA (6). Differences between results at 36 weeks PMA and post term were assessed for statistical significance using the Mann Whitney U-Test. Twelve infants were included in this and our previous study (6), differences in the time constant results in the two positions at 36 weeks PMA and post term were assessed for statistical significance using the paired Wilcoxon Rank Sum test. Using all the results from the two studies, Spearman's correlation co-efficients were calculated to determine the strength of any relationships between the change in minute volume or the time constant and postmenstrual age. Analysis was performed using SPSS version 12.0, SPSS Inc, Chicago, Illinois 60606, USA.

\section{Sample Size}

In a previous study (5), we demonstrated that the coefficient of repeatability of TC was 11 seconds. Recruitment of 20 infants allowed, with at least $80 \%$ power at the $5 \%$ level, detection of a difference in the Tc between positions of at least 11 seconds.

\section{Patients}

Twenty infants (10 males), median gestational age 30 (range 24-32) weeks and birthweight 1190 (SD 326) (range 543-1730) gm (mean $( \pm S D)$ z score $0 \pm 1$ ) were recruited. They were studied at a postmenstrual age of 45 (41-47) weeks and weight of 3.72 (SD 0.95) (range 1.85.3) kgs (mean $( \pm S D)$ z score $0 \pm 1$ ). Five infants were oxygen dependent beyond 36 weeks PMA, but none were oxygen dependent at the time of study. None of the infants were receiving any medication when studied. Three mothers had smoked during pregnancy. The twelve infants included in our previous study (6) and this study had a median gestational age of 29 (range 24-32) weeks and birth weight 1230 (range 730-1730) gms. The study was approved by the King's College Hospital Research Ethics Committee. 


\section{RESULTS}

The addition of the dead space resulted in an increase in minute volume in both the prone and supine positions (Table 1). The difference between positions in the percentage change in minute volume was not statistically significant. The time constant of the response was significantly longer in the prone compared to the supine position $(p=0.002)$ (Table 1) (Figure 2). There were no significant differences in the respiratory timings or minute ventilation at baseline between the two positions (Table 1). The median $T_{i}$ was significantly longer in the prone compared to the supine position after the dead space was added (Table 1).

The median MIOP tended to be lower in the prone compared to the supine position $(p=0.07)$, but there was no significant correlations between the response to tube breathing and MIOP in either position. The median $\mathrm{P}_{0.1}$ was significantly lower in the prone compared to the supine positions $(p=0.003)$, but there were no significant correlations between the response to tube breathing and $\mathrm{P}_{0.1}$ in either position. The median FRC was significantly higher in the prone compared to the supine position $(p=0.031)$ (Table 1$)$.

Comparisons of the results of the infants studied at 36 weeks PMA and those studied post term revealed no significant differences in the median changes in minute volume or the time constant, but that the median MIOP was significantly greater in both positions post term $(p<0.001)$ (Table 2$)$. The change in minute ventilation was not significantly correlated with postmenstrual age in either the supine $(p=0.697)$ or the prone $(p=0.25)$ position. The mean difference in the time constants between the prone and supine positions was 8.3 seconds at 36 weeks PMA and 21.3 seconds post term respectively. The mean difference between the difference at the two time periods was 13.4 seconds ( $95 \%$ confidence intervals of the differences was $-2.5,28.6)(p=0.098)$. In the twelve infants who had been assessed at 36 weeks PMA and post term, the median time constant at 36 weeks PMA in the supine position was 25 (range 10-51) seconds and in the prone position was 34 (range 15-96) seconds $(p=0.019)$ and post term in the supine position was 26 (range 2-40) seconds and in the prone 
position was 38 (range $15-85)$ seconds $(p=0.008)$. There was no significant difference in the difference in the time constant results in the supine and prone positions between the two time periods. Overall, the time constant of the response to added dead space had a significant positive correlation with postmenstrual age in the prone $(r=0.305, p=0.047)$, but not the supine $(r=0.031, p=0.844)$ position. 


\section{DISCUSSION}

We have demonstrated that at a high risk age for SIDS (2), the response to added dead space in prematurely born infants was poorer in the prone compared to the supine position, as the time constant was significantly longer in the prone position. Hypercarbia is the most important stimulus to ventilation during added dead space (tube breathing), as measurements in air and 30\% oxygen yielded similar results (12) and no effect of resistance was found in experiments involving prematurely born infants (12). Our results then suggest that prematurely born infants at the high risk age for SIDS have a dampened response to hypercarbia in the prone position. The time constant during tube breathing is shorter in active compared with quiet sleep (3). To avoid such a confounding effect, infants were always tested when they were in quiet sleep. Maternal smoking during pregnancy is associated with an impaired response to added dead space (5). Three infants studied had mothers who were smokers, but our results were not biased by their inclusion as we compared the response of all the infants in two positions.

The dampened response to added dead space in the prone position may indicate reduced respiratory drive in that position. Indeed we did find that the $P_{0.1}$ was significantly lower in the prone compared to the supine position. $\mathrm{P}_{0.1}$ is influenced by respiratory muscle strength, but there was no significant difference in the median MIOP between positions. As we had demonstrated previously (13), the median FRC was higher in the prone compared to the supine position. Although the difference was significant, however, the magnitude of the difference was relatively small and unlikely to influence MIOP (14). It is possible, however, that the difference in FRC may have affected the strength of the Hering-Breuer inflation reflex. The Hering-Breuer inflation reflex which terminates inspiration and prolongs expiration in response to lung inflation (15) is stronger in the prone compared to the supine position $(16,17)$. Differences in the strength of the reflex between positions in prematurely born infants have been shown to be significantly correlated with differences in lung volume (17). In addition, in healthy adults the strength of the Hering-Breuer reflex was directly 
proportional to increasing lung volume (18). A possible explanation for our results, then, is that the significantly increased FRC in the prone position was associated with increased feedback from pulmonary stretch receptors which reduced ventilatory drive as evidenced by a lower $\mathrm{P}_{0.1}$ and a longer time constant in response to added deadspace.

Ideally, to have assessed the effect of postmenstrual age on the response to dead space, we would have undertaken serial measurements on the same group of babies, but were unable to do this only in a subset of our study population. The same equipment and methodology, however, was used in both studies. Indeed, one of the researchers was involved in making certain of the measurements in both studies and the same team analysed the results of the two studies using the same techniques. The only difference in the two studies was in the first one (6), the infants were studied while awake and in the one currently reported the infants were studied while in quiet sleep. In quiet sleep there is less variability in minute volume than when infants are in active sleep or awake, but this would not affect the time constant of the response. We, thus, feel it is appropriate to pool the results of the two studies.

Despite the median MIOP being significantly greater post term than at 36 weeks PMA, the response to added dead space was not significantly better, suggesting respiratory muscle strength (above a crucial level) may not be a major determinant of the response to added dead space. There were no statistically significant differences in the time constants in either position post term compared to 36 weeks PMA. The paired analysis in the study population overall and in the subgroup, however, demonstrated the levels of significance were greater post term than at 36 weeks PMA, indicating that a greater proportion of the infants had longer time constants in the prone compared to the supine position post term than at 36 weeks PMA. We also found a significant correlation between the time constant of the response to added dead space and postmenstrual age in the prone position, that is, the response to added dead space was slower with increasing postmenstrual age. A possible explanation for the reduced response rate to added dead space with increasing postnatal age might be maturational changes in the Hering-Breuer inflation reflex. There are few 
longitudinal studies of maturational changes in the Hering-Breuer reflex, but in term born infants, the strength of the reflex appears to diminish between two and twelve months of age (19). In prematurely born infants an initial increase in the strength of the reflex from birth to 40 weeks PMA has been described, but the reflex strength was lower when the infants were examined four months after their expected date of delivery (20). Others (21) have demonstrated a reduction in the strength of the reflex in prematurely born infants from birth, but the study was performed over thirty years ago. Thus, it (21) would have included infants not exposed to either antenatal steroids or postnatal surfactant and with different lung function from the present population of very prematurely born infants. In addition, it is likely the infants were studied supine (21). We speculate that the strength of the Hering-Breuer reflex in the prone position may be maximal in prematurely born infants at the critical age for SIDS and could contribute to their reduced response to added deadspace.

In conclusion, we have demonstrated that prematurely born infants at the high risk age for SIDS had a poorer response to an added dead space in the prone compared to the supine position. In addition, the rate of response to the added dead space in the prone position was significantly damped with increasing postmenstrual age up to the critical age for SIDS. These findings lend support to the hypothesis that a poorer response to a stress may contribute to the increased vulnerability of prematurely born infants to SIDS in the prone position. 


\section{REFERENCES}

1. Vennemann MM, Bajanowski T, Brinkmann B, Jorch G, Sauerland C, Mitchell EA. Sleep environment risk factors for sudden infant death syndrome: the German Sudden Infant Death Syndrome Study. Pediatrics 2009;123(4):1162-1170.

2. Halloran DR, Alexander GR. Preterm delivery and age of SIDS death. Ann Epidemiol 2006;16(8):600-606.

3. Upton CJ, Milner AD, Stokes GM, Wilson AJ. Dynamic responses to tube breathing during the first 10 days of life. Pediatr Pulmonol 1990;9(2):72-79.

4. Chong DS, Yip PS, Karlberg J. Maternal smoking: an increasing unique risk factor for sudden infant death syndrome in Sweden. Acta Paediatr 2004;93(4):471-478.

5. Bhat RY, Broughton S, Khetriwal B, Rafferty GF, Hannam S, Milner AD, Greenough A. Dampened ventilatory response to added dead space in newborns of smoking mothers. Arch Dis Child Fetal Neonatal Ed 2005;90(4):F316-319.

6. Rao H, Saiki T, Landolfo F, Smith AP, Hannam S, Rafferty GF, Milner AD, Greenough A. Position and ventilatory response to added dead space in prematurely born infants. Pediatr Pulmonol 2009;44(4):387-391

7. Oyen N, Markestad T, Skaerven R, Irgens LM, Helweg-Larsen K, Alm B, Norvenius G, Wennergren G. Combined effects of sleeping position and prenatal risk factors in sudden infant death syndrome: the Nordic Epidemiological SIDS Study. Pediatrics $1997 ; 100(4): 613-621$.

8. Dimitriou G, Greenough A, Pink L, McGhee A, Hickey A, Rafferty GF. Effect of posture on oxygenation and respiratory muscle strength in convalescent infants. Arch Dis Child Fetal Neonatal Ed 2002;86(3):F147-150.

9. Bhat RY, Leipala JA, Singh NR, Rafferty GF, Hannam S, Greenough A. Effect of posture on oxygenation, lung volume, and respiratory mechanics in premature infants studied before discharge. Pediatrics 2003;112(1 Pt 1):29-32.

10. Hey EN. The relation between environmental temperature and oxygen consumption in the new-born baby. J Physiol 1969;200(3):589-603. 
11. Dimitriou G, Greenough A, Laubscher B. Lung volume measurements immediately after extubation by prediction of "extubation failure" in premature infants. Pediatr Pulmonol 1996;21(4):250-254.

12. Upton CJ. Apnoea of prematurity. MD University of Nottingham 1994.

13. Saiki T, Rao H, Landolfo F, Smith A, Hannam S, Rafferty GF, Greenough A. Sleeping position, oxygenation and lung function in prematurely born infants studied post term. Arch Dis Child 2009;94:F133-137.

14. McCool FD, Tzelepis GE, Leith DE, Hoppin FG, Jr. Oxygen cost of breathing during fatiguing inspiratory resistive loads. J Appl Physiol 1989;66(5):2045-2055.

15. Hering, E. Die Selbststeuerung der Atmung durch den Nervus vagus. Wien: Sitzungsberichte der mathematisch - naturwissenschaftlichen Klasse der kaiserlichen Akademie der Wissenschaften Abtheilung, str. 1868;57:672-677.

16. Hand IL, Noble L, Geiss D. The effects of positioning on the Hering-Breuer reflex in the preterm infant. Pediatr Pulmonol 2007;42(1):37-40.

17. Landolfo F, Saiki T, Peacock J, Hannam S, Rafferty GF, Greenough A. Hering-Breuer reflex, lung volume and position in prematurely born infants. Pediatr Pulmonol 2008;43(8):767-771

18. Tryfon S, Kontakiotis T, Mavrofridis E, Patakas D. Hering-Breuer reflex in normal adults and in patients with chronic obstructive pulmonary disease and interstitial fibrosis. Respiration 2001;68(2):140-144.

19. Rabbette PS, Costeloe KL, Stocks J. Persistence of the Hering-Breuer reflex beyond the neonatal period. J Appl Physiol 1991;71(2):474-480.

20. Stocks J, Dezateux C, Hoo AF, Rabbette PS, Costeloe K, Wade A. Delayed maturation of Hering-Breuer inflation reflex activity in preterm infants. Am J Respir Crit Care Med 1996;154(5):1411-1417.

21. Olinsky A, Bryan MH, Bryan AC. Influence of lung inflation on respiratory control in neonates. J Appl Physiol 1974;36(4):426-429. 


\section{FIGURE LEGEND:}

Figure 1: Apparatus used to measure the response to added dead space.

(A) The arrows show the direction of gas flow before the dead space is added.

(B) When the three way tap is turned to be in the vertical position, this diverts the bias flow from the face mask and the infant has to breathe from the added dead space tube.

Figure 2: The time constants of the response related to position at 36 weeks PMA and post term

- individual data are demonstrated by linked data points. 